\title{
Association of serum magnesium level with resistant hyperlipidemia in diabetic and hypertensive patients
}

\author{
Pardis Kaveh $^{1}{ }^{\circledR}$, Afsaneh Malekpour Tehrani ${ }^{2}$, Saeid Mardani ${ }^{1 *}$ \\ ${ }^{1}$ Departments of Internal Medicine, Shahrekord University of Medical Sciences, Shahrekord, Iran \\ ${ }^{2}$ Social Medicine, Shahrekord University of Medical Sciences, Shahrekord, Iran
}

\section{A R T I CLE IN F O \\ Article Type: \\ Original \\ Article History: \\ Received: 30 April 2018 \\ Accepted: 9 July 2018 \\ Published online: 23 August 2019}

\section{Keywords:}

Hypertension

Hyperlipidemia

Diabetes mellitus

Triglyceride

\begin{abstract}
A B S T R A C T
Introduction: Both diabetes mellitus and hypertension are aspects of metabolic syndrome.

Objectives: The aim of this study was to determine the relationship between serum magnesium level with resistant hyperlipidemia in a group of diabetic and hypertensive patients.

Patients and Methods: The present cross-sectional study was carried out on 90 hypertensive and diabetic patients who referred to outpatient university clinic in Shahrekord ( 45 hypertensive and 45 diabetic patients). Included patients had high triglyceride levels despite 8 weeks of treatment with lipid-lowering agents.

Results: There was an inverse significant relationship between serum magnesium and triglyceride levels in diabetic patients $(P=0.002, \mathrm{r}=-0.458)$, however, this correlation was not significant in hypertensive patients $(P=0.754, \mathrm{r}=0.048)$.

Conclusion: This study showed, serum magnesium may affect triglycerides levels in diabetic patients, however, our finding requires further investigation with larger population.
\end{abstract}

\section{Implication for health policy/practice/research/medical education:}

in a study on 90 hypertensive and diabetic patients ( 45 hypertensive and 45 diabetic patients), we found, an inverse significant relationship between serum magnesium and triglyceride level in diabetic patients $(P=0.002, r=-0.458)$. Our study showed that serum magnesium may affect triglycerides levels in diabetic patients.

Please cite this paper as: Kaveh P, Malekpour Tehrani A, Mardani S. Association of serum magnesium level with resistant hyperlipidemia in diabetic and hypertensive patients. J Nephropharmacol. 2020;9(1):e07. DOI: 10.15171/npj.2020.07.

\section{Introduction}

Diabetes mellitus, commonly, is known to be a metabolic disease characterized by high blood sugar levels over a long-period of time (1). There are many lipoprotein disorders in patients with uncontrolled diabetes. These metabolic disorders are due to the excessive production of triglyceride-rich lipoproteins of the liver, which is due to low levels of high-density lipoproteins (HDL). These patients also suffer from hypertriglyceridemia, which is due to a decrease in adipose tissue and lipoprotein lipase activity in the muscle tissues. Reduced HDL-C levels are due to plasma lipoprotein lipase (LPL) in catabolism of triglyceride-rich lipoproteins (2).

Hypertension is a chronic disease, in which arterial blood pressure rises. High blood pressure, can result in significant problems and increases the risk of cardiac and renal disease, stroke and also death $(3,4)$.

Hyperlipidemia is common in patients with hypertension, but the causes of this condition are unknown. Additionally, treatment of hypertension with thiazide diuretics increases the risk of hyperlipidemia.

Magnesium $(\mathrm{Mg})$ is the fourth most abundant cation in the body, as well as the second intracellular cation after potassium. For many enzymes involved in the metabolism of carbohydrates and lipids, $\mathrm{Mg}$ is an important cofactor (5). Hypomagnesemia is one of the most common electrolyte disorders in diabetic patients (6). Numerous studies have shown a relationship between magnesium deficiency with insulin resistance, diabetes, and hyperlipidemia (5). Additionally, epidemiological studies have shown an inverse relationship between magnesium intake and the level of blood pressure and the incidence of hypertension. It was also shown that hypertensive patients have lowered serum and intracellular magnesium than normal people (7). $\mathrm{Mg}$ plays an important role in lipoprotein lipase enzyme activity and removes triglyceride from blood. It is also essential for the activity of the enzyme, lecithin cholesterol acyltransferase 
(LCAT), which converts free cholesterol into cholesterol esters and causes liver inflammation. Pyrophosphatase, an enzyme involved in lipid metabolism, also requires $\mathrm{Mg}$ for its activity. Therefore, in magnesium deficiency, enzymes are not properly efficient and accordingly dyslipidemia may happen (5). Recently it was shown that normal population with lower Mg levels, had lower HDL-C, higher triglyceride (TG), and also total cholesterol serum values (8).

Hyperlipidemia increases the incidence of cardiovascular events and subsequent mortalities in patients. Lipid abnormalities such as lowered serum HDL-C levels and increased triglyceride blood levels are common in type 2 diabetes. Accordingly, lipid abnormalities in type 2 diabetes and hypertensive patients, can be considered as a cause for development of atherosclerosis. The relationship between magnesium and cardiovascular risk factors has been proven in previous studies, however, there are many contradictory findings regarding the effect of magnesium on lipid profiles, as well as the control of blood sugar in diabetic patients.

\section{Objectives}

Several studies have also proven the relationship between magnesium and hypertension, however few studies have been conducted on this subject. Serum magnesium is not commonly measured in diabetic and hypertensive patients, while recent investigation showed various metabolic complications have been attributed to hypomagnesemia. Hence this study was designed to detect the relationship between plasma magnesium levels and lipid profiles in diabetic and hypertensive individuals.

\section{Patients and Methods}

\section{Study design}

The present cross-sectional study was carried out on 90 hypertensive or diabetic patients who referred to outpatient university clinic in Shahrekord ( 45 hypertensive patients and 45 diabetic patients). Patients had high triglyceride levels despite eight weeks of treatment with lipid-lowering agents. Samples were gradually selected using convenience sampling method. Blood pressure was measured and recorded using an appropriate cuff under standard conditions. A total of $5 \mathrm{cc}$ blood samples was taken from the patients after obtaining their consent letter, then blood cholesterol, triglyceride, HDL-C, low density lipoprotein (LDL-C), fasting blood glucose, and serum magnesium level were measured by standard methods.

\section{Ethical issues}

Human rights were respected in accordance with the Helsinki Declaration 1975, as revised in 1983. The ethical committee of Shahrekord University of Medical Sciences (ethical code; IR.SKUMS.REC.1396.280) approved the study. The informed consents were taken from the patients. Besides, this study was extracted from the M.D, thesis of Pardis Kaveh at this University.

\section{Statistical analysis}

Collected, data entered in SPSS version 18 and analyzed using descriptive statistics, Pearson's or Spearman correlation's coefficient test, and also $t$ test according to the distribution of data. Quantitative variables were investigated for normal distribution using KolmogorovSmirnov test. All statistical differences were considered significant at the level of $P$ value lower than 0.05 .

\section{Results}

Out of 90 participants, 45 patients (50\%) were included in group 1 (diabetic patients) and $45(50 \%)$ in group 2 (hypertensive patients). The mean $\pm \mathrm{SD}$ of age, triglyceride, cholesterol, HDL-C, LDL-C, and serum magnesium of all participants was $60.41 \pm 16.08$ years, $216.76 \pm 94.51$ $\mathrm{mg} / \mathrm{dL}, \quad 281.34 \pm 38.31 \mathrm{mg} / \mathrm{dL}, \quad 38.53 \pm 11.15 \mathrm{mg} / \mathrm{dL}$, $201.04 \pm 44.93 \mathrm{mg} / \mathrm{dL}$ and $1.97 \pm 0.45 \mathrm{mg} / \mathrm{dL}$, respectively. We found no statistically significant relationship between magnesium and cholesterol levels in total patients $(P=0.146, \quad \mathrm{r}=-0.155)$. Additionally, the relationship of magnesium with HDL-C $(P=0.228, r=-0.12)$, and LDL-C $(P=0.751, r=-0.34)$ was also not significant in all cases. Spearman's correlation analysis also showed no statistically significant relationship between magnesium level and fasting blood glucose in diabetic patients $(P=0.342, r=0.145)$. Similarly, no significant relationship between serum magnesium with systolic and diastolic blood pressure in group 2 was detected $(P=0.893, \mathrm{r}=0.21$ and $P=0.347, \mathrm{r}=-0.143$ respectively).

We also found, a significant correlation between serum magnesium and triglyceride level in group $1(P=0.002$, $\mathrm{r}=-0.458$; Spearman's test, Figure 1$)$, since in group 2 this association was not significant $(P=0.75, \mathrm{r}=0.048)$.

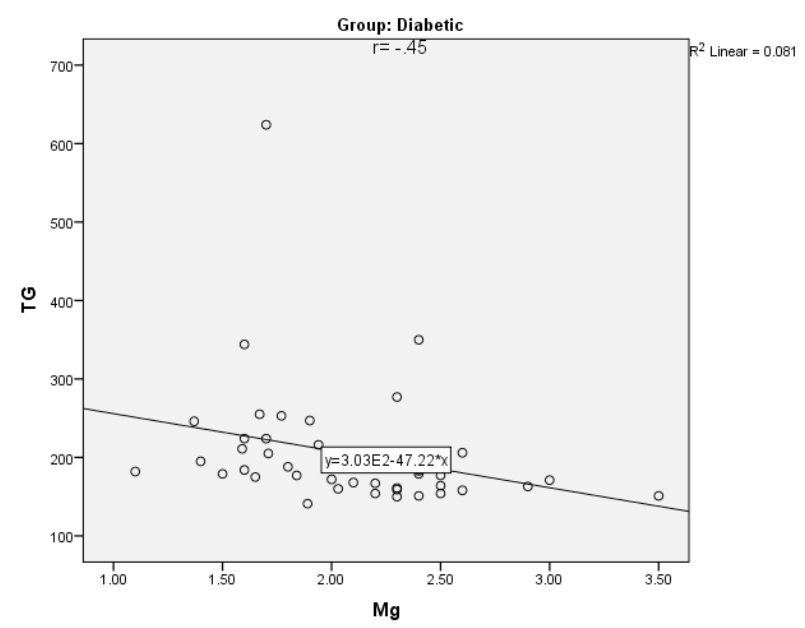

Figure 1. Significant correlation between serum magnesium and triglyceride level in diabetic patients $(P=0.002, r=-0.458$; Spearman's test). 
Table 1. Data of the patients

\begin{tabular}{|c|c|c|c|c|c|}
\hline & Group & $\mathbf{N}$ & Mean & Std. Deviation & Std. Error Mean \\
\hline \multirow{2}{*}{ Age (years) } & Diabetic & 45 & 61.56 & 15.494 & 2.310 \\
\hline & HTN & 45 & 59.27 & 16.755 & 2.498 \\
\hline \multirow{2}{*}{ TG (mg/dL) } & Diabetic & 45 & 204.27 & 78.639 & 11.723 \\
\hline & HTN & 45 & 229.24 & 107.548 & 16.032 \\
\hline \multirow{2}{*}{ Cholesterol (mg/dL) } & Diabetic & 45 & 282.18 & 37.901 & 5.650 \\
\hline & HTN & 45 & 280.51 & 39.141 & 5.835 \\
\hline \multirow{2}{*}{$\mathrm{HDL}-\mathrm{C}(\mathrm{mg} / \mathrm{dL})$} & Diabetic & 45 & 35.67 & 8.868 & 1.322 \\
\hline & HTN & 45 & 41.40 & 12.503 & 1.864 \\
\hline \multirow{2}{*}{ LDL-C (mg/dL) } & Diabetic & 45 & 206.69 & 45.206 & 6.739 \\
\hline & HTN & 45 & 195.40 & 44.451 & 6.626 \\
\hline \multirow{2}{*}{$\mathrm{Mg}(\mathrm{mg} / \mathrm{dL})$} & Diabetic & 45 & 2.0916 & 0.47487 & 0.07079 \\
\hline & HTN & 45 & 1.8629 & 0.40823 & 0.06086 \\
\hline
\end{tabular}

Likewise, no significant correlation between serum magnesium and cholesterol in group one $(P=0.11$, $\mathrm{r}=-0.238)$ and group two $(P=0.59, \mathrm{r}=-0.081)$ was detected. Accordingly, the association of serum magnesium with LDL-C in group one $(P=0.91, \mathrm{r}=-0.16)$ and group two $(P=0.4, r=-0.12)$ was not significant. Besides HDL-C in group one $(P=0.64, \mathrm{r}=-0.071)$ and group two $(P=0.47$, $\mathrm{r}=-0.1)$ were not associated with serum magnesium.

\section{Discussion}

The present study was carried out on 90 hypertensive and diabetic patients ( 45 hypertensive patients and 45 diabetic patients) with had high triglyceride levels despite a treatment period of 8 weeks with lipid-lowering drugs. In this study we found, plasma magnesium had relationship with serum triglyceride level in diabetic patients. However, the serum magnesium level does not correlate with fasting blood glucose, cholesterol, HDL-C, or LDL-C levels. Our results also showed that serum magnesium levels were not correlated with level of lipids or systolic and diastolic blood pressure in hypertensive patients. Diabetes mellitus is the most common disorder among endocrine disorders, which is associated with hypomagnesemia. Numerous studies have already shown that Mg levels are lower in diabetic patients (9-11). Reduced Mg level may cause insulin resistance $(12,13)$ and insufficient glucose control (14-16), and also dyslipidemia in diabetic patients (17). Previous studies have shown a significant negative correlation between $\mathrm{Mg}$ and fasting blood glucose (FBS) $(9,11)$. However, our study didn't show a significant correlation between $\mathrm{Mg}$ and FBS, which requires further larger studies. Marhalle et al (18) concluded that diabetes, dyslipidemia, and hypertension were inversely related to serum $\mathrm{Mg}$, however we found no significant correlation between serum $\mathrm{Mg}$ with LDL-C, HDL-C, and triglyceride levels in hypertensive patients. We found, a significant correlation between serum $\mathrm{Mg}$ and triglyceride levels in diabetic patients. This finding is consistent with the result of a study by Arpaci et al (19). Various studies have suggested a direct relationship between $\mathrm{Mg}$ level and systolic blood pressure (20-22), however, results of the present study did not show this relationship while further studies are necessary for this reason.

\section{Conclusion}

Results of the current study showed that magnesium $(\mathrm{Mg})$ can affect triglycerides levels in diabetic patients suggesting an inverse relationship between serum magnesium and triglyceride levels. However, there is no relationship between the magnesium serum level with fasting blood glucose, cholesterol, HDL-C, or LDL-C levels. Moreover, there is no relationship between serum magnesium levels and the level of lipid profiles or to the level of systolic or diastolic hypertension in hypertensive patients. Considering the effect of serum magnesium level on reducing triglyceride levels in diabetic patients indicated in this study and the need for correction of lipid profiles in these patients, the administration of magnesium supplements in the treatment of diabetic patients may be necessary.

\section{Limitation of the study}

Our study conducted on a limited sample size of patients with resistant hyperlipidemia. This study needs further investigation on larger samples and also on all patients with hyperlipidemia without anti-lipid treatment.

\section{Authors' contribution}

Design of the study and selecting the patients; SM; gathering the patients and data entering; PK. Data analysis; AMT. Primary draft; PK. Final edit; SM. All authors read and signed the paper manuscript.

\section{Conflicts of interest}

The authors declared no competing interests.

Ethical considerations

Ethical issues including plagiarism, double publication, and redundancy have been completely observed by the authors. 


\section{Funding/Support}

This research was funded by Shahrekord University of Medical Sciences. This study was extracted from the M.D, thesis of Pardis Kaveh at this University.

\section{References}

1. Alberti KG, Zimmet P, Shaw J. Metabolic syndrome--a new world-wide definition. A Consensus Statement from the International Diabetes Federation. Diabet Med. 2006; 23:469-80. doi: 10.1111/j.1464-5491.2006.01858. x.

2. Abbate SL, Brunzell JD. Pathophysiology of hyperlipidemia in diabetes mellitus. J Cardiovasc Pharmacol. 1990;16 Suppl 9:S1-7.

3. Conn VS, Ruppar TM, Chase JD. Blood pressure outcomes of medication adherence interventions: systematic review and meta-analysis. J Behav Med. 2016; 39:1065-75. doi: 10.1007/s10865-016-9730-1.

4. Ames RP. Hyperlipidemia in hypertension: causes and prevention. Am Heart J. 1991;122:1219-24.

5. Deepti R, Nalini G. Magnesium plays a salient role in the cells. J Clin Biomed Sci. 2014;4:341-5.

6. Longstreet DA, Heath DL, Panaretto KS, Vink R. Correlations suggest low magnesium may lead to higher rates of type 2 diabetes in Indigenous Australians. Rural Remote Health. 2007; 7:843.

7. Kawano Y, Matsuoka H, Takishita S, Omae T. Effects of magnesium supplementation in hypertensive patients: assessment by office, home, and ambulatory blood pressures. Hypertension. 1998;32:260-5.

8. Randell EW, Mathews M, Gadag V, Zhang H, Sun G. Relationship between serum magnesium values, lipids and anthropometric risk factors. Atherosclerosis. 2008; 196:413-9. doi: 10.1016/j.atherosclerosis.2006.11.024.

9. Kim DJ, Xun P, Liu K, Loria C, Yokota K, Jacobs DR Jr, He $\mathrm{K}$. Magnesium intake in relation to systemic inflammation, insulin resistance, and the incidence of diabetes. Diabetes Care. 2010;33:2604-10. doi: 10.2337/dc10-0994.

10. Dasgupta A, Sarma D, Saikia UK. Hypomagnesemia in type 2 diabetes mellitus. Indian J Endocrinol Metab. 2012; 16:1000-3. doi: 10.4103/2230-8210.103020.

11. Sales CH, Pedrosa LF, Lima JG, Lemos TM, Colli C. Influence of magnesium status and magnesium intake on the blood glucose control in patients with type 2 diabetes.
Clin Nutr. 2011;30:359-64. doi: 10.1016/j.clnu.2010.12.011.

12. Corica F, Allegra A, Ientile R, Buemi M, Corsonello A, Bonanzinga $S$, et al. Changes in plasma, erythrocyte, and platelet magnesium levels in normotensive and hypertensive obese subjects during oral glucose tolerance test. Am J Hypertens. 1999;12:128-36. doi: 10.1016/s08957061(98)00174-5.

13. Wasada T, Katsumori K, Saeki A, Saito S, Omori Y. Urinary albumin excretion rate is related to insulin resistance in normotensive subjects with impaired glucose tolerance. Diabetes Res Clin Pract. 1997; 34:157-62.

14. Pickup JC, Chusney GD, Crook MA, Viberti GC. Hypomagnesaemia in IDDM patients with microalbuminuria and clinical proteinuria. Diabetologia. 1994;37:639.

15. Arslanoğlu I, Günöz H, Bundak R, Saka N. Hypomagnesaemia in childhood IDDM and risk of nephropathy. Diabetologia. 1995;38:629.

16. Mather HM, Levin GE. Magnesium status in diabetes. Lancet. 1979;1(8122):924.

17. Reverter JL, Sentí M, Rubiés-Prat J, Lucas A, Salinas I, Pizarro E, et al. Relationship between lipoprotein profile and urinary albumin excretion in type II diabetic patients with stable metabolic control. Diabetes Care. 1994;17:18994. doi: 10.2337/diacare.17.3.189.

18. Mahalle N, Kulkarni MV, Naik SS. Is hypomagnesaemia a coronary risk factor among Indians with coronary artery disease? J Cardiovasc Dis Res. 2012;3:280-6. doi: 10.4103/0975-3583.102698.

19. Arpaci D, Tocoglu AG, Ergenc H, Korkmaz S, Ucar A, Tamer A. Associations of serum Magnesium levels with diabetes mellitus and diabetic complications. Hippokratia. 2015;19:153-7.

20. Joffres MR, Reed DM, Yano K. Relationship of magnesium intake and other dietary factors to blood pressure: the Honolulu heart study. Am J Clin Nutr. 1987;45:469-75. doi: 10.1093/ajcn/45.2.469.

21. Guerrero-Romero F, Rodríguez-Morán M. Low serum magnesium levels and metabolic syndrome. Acta Diabetol. 2002;39:209-13. doi: 10.1007/s005920200036.

22. Whelton PK, Klag MJ. Magnesium and blood pressure: review of the epidemiologic and clinical trial experience. Am J Cardiol. 1989;63:26G-30G.

Copyright $\odot 2020$ The Author(s); Published by Published by Society of Diabetic Nephropathy Prevention. This is an open-access article distributed under the terms of the Creative Commons Attribution License (http://creativecommons.org/licenses/by/4.0), which permits unrestricted use, distribution, and reproduction in any medium, provided the original work is properly cited. 